\title{
Crohn's Disease Treatment Expenditures over Fifteen Years of Follow-Up
}

Graziele Duarte Machado $^{1^{*}}$, Brian Godman², Elham Rahme ${ }^{3}$, Mariangela Leal Cherchiglia ${ }^{4}$, Francisco de Assis Acurcio ${ }^{5}$, Eli Iola Gurgel Andrade $^{4}$, Juliana Alvares ${ }^{5}$, Vânia Eloisa de Araújo ${ }^{6}$, Lana Claudinez dos Santos ${ }^{6}$ and Augusto Afonso Guerra Júnior

${ }^{1}$ Postgraduate Program of Medicines and Pharmaceutical Assistance, Federal University of Minas Gerais, Brazil

${ }^{2}$ Strathclyde Institute of Pharmacy and Biomedical Sciences, UK

${ }^{3}$ Division of Clinical Epidemiology, McGill University Health Centre, Canada

${ }^{4}$ Department of Preventive and Social Medicine, Federal University of Minas Gerais, Brazil

${ }^{5}$ Department of Social Pharmacy, Federal University of Minas Gerais, Brazil

${ }^{6}$ Pontifical Catholic University of Minas Gerais, Brazil

\begin{abstract}
Background: The increasing Crohn's Disease (CD) prevalence worldwide has contributed to CD related healthcare resource use increase and the disease treatment has a considerable economic burden, varying between countries. The aim of this study was to assess the direct medical cost of CD treatment over fifteen years of follow up in Brazil.

Methods: A total of $46,886 \mathrm{CD}$ patients were included. Patients were identified from the Brazilian public health system databases between 2000 and 2014. The mean annual expenditure was calculated for each patient. Expenditures included the costs of all (CD-related or not) medications, diagnostics and monitoring exams, outpatient care and hospitalizations. Multivariate analyses were conducted to evaluate the relation between demographic and clinical variables in mean annual expenditure.
\end{abstract}

Results: The total expenditures were US\$ 844.24 million over the entire study period (2000-2014) with annual mean $[95 \% \mathrm{Cl}$ ] of US $\$ 3,451.0[3,399.2-3,502.7]$ per patient. Of the total expenditures, $90.3 \%$ were for CD medications with Tumor Necrosis Factor inhibitors being the primary cost driver, accounting for $76.0 \%$ of the total medication cost in 2000 and $85.9 \%$ in 2014 . Hospitalization cost accounted for $3.0 \%$ of the overall total expenditures. The multivariate analyses showed that gender, age, region of residence, and medication used at study entry can predict DC treatment costs.

Conclusion: In Brazil, the annual direct medical cost of $C D$ treatment is substantial. Medication cost, in particular that of anti-TNF alpha agents is increasingly the most important cost driver.

Keywords: Crohn's disease; Health costs; Cost analysis

\section{Introduction}

Crohn's Disease (CD) is an inflammatory bowel disease (IBD) characterized by chronic inflammation of the gastrointestinal tract affecting most frequently the ileum and colon [1]. The etiology is not completely understood but typically involves the interaction of environmental, genetic, and immune factors [1-4]. Characteristic symptoms are chronic diarrhea (more than 6 weeks), abdominal pain, weight loss, blood and/or mucus in the stool. Extra-intestinal manifestations are frequent and can affect the joints, skin, eyes and the hepatobiliary tract [5].

As a relapsing disease, its natural history is characterized by periods of active disease with graded clinical severity usually classified as mild, moderate and severe, and periods of remission [6]. The treatment is based on drug or surgery induction of remission, followed by maintenance with medicines in combination with lifestyle changes [7]. Medical treatment increasingly includes the earlier use of immunomodulators and biologic agents such as the Tumor Necrosis Factor alpha inhibitors (anti-TNF alpha), especially in Western Countries, [8-12] although treatment with these medications varies between countries according to drug reimbursement policy and patient co-payment $[3,13]$.

The incidence and prevalence of IBD is traditionally higher in developed countries especially in the United States (US), Canada and countries of Western Europe, but reports of increasing cases have also appeared in other regions such as Africa, Asia and Latin America [14]. In Europe, the highest reported incidence and prevalence of $\mathrm{CD}$ was
12.7 per 100,00 person-year and 322 per 100,000, respectively [15]. In the US annual incidence range from approximately 3 to 20 cases per 100,000 population $[4,16]$, and it was estimated that up to 3 million Americans had IBD in 2015, representing 1.3\% of the population [4] In Brazil, epidemiological data about IBD are scarce and only a few local or regional studies have been conducted. Nonetheless, limited data point to an increase in CD prevalence over recent years [17-19].

$\mathrm{CD}$ onset is more common between the second and fifth decade of life, peaking between 20 and 30 years of age and then decreasing to peak again to a smaller extent after age 50 years [4]. CD is associated with high morbidity. Hence due to its early onset, it has a significant impact on the patient's quality of life and work productivity. CDrelated long-term cost is substantial to the patient, health care system, and society $[12,14,20]$.

Cost analysis studies conducted in various countries have agreed that the economic burden of $\mathrm{CD}$ is considerable, although their

*Corresponding author: Graziele Duarte Machado, Postgraduate Program of Medicines and Pharmaceutical Assistance, Federal University of Minas Gerais, Brazil, Tel: +55313409-4025; E-mail: grazidmachado@gmail.com

Received January 15, 2018; Accepted January 25, 2018; Published February 02, 2018

Citation: Machado GD, Godman B, Rahme E, Cherchiglia ML, Acurcio FDA, et al. (2018) Crohn's Disease Treatment Expenditures over Fifteen Years of Follow-Up. Pharmacoeconomics 3: 115. doi:10.4172/2472-1042.1000115

Copyright: (c) 2018 Machado GD, et al. This is an open-access article distributed under the terms of the Creative Commons Attribution License, which permits unrestricted use, distribution, and reproduction in any medium, provided the original author and source are credited. 
reported figures varied between countries [16,20,21]. For instance, recent studies have estimated the total costs of $\mathrm{CD}$, including both direct and indirect costs, to be between US $\$ 10.9$ billion and US $\$ 15.5$ billion in the US, US $\$ 2.8$ billion in Canada (for IBD including CD and ulcerative colitis), and between $€ 2.1$ billion and $€ 16.7$ billion in Europe [12,21]. Mean total CD-related costs per patient per year have also varied between Western Countries, ranging between US\$18,962 to US $\$ 26,192$ in the US [22] with higher costs for patients with fistulizing disease, to $€ 18,525$ in Germany [23], €15,521 in Italy [24] and $€ 6,808$ in Spain [25]. Costs per patient are currently lower in Eastern European countries where there is limited access to biological therapies that are only available with high patient co-payments [3].

With the increasing prevalence of $\mathrm{CD}$, and growing constraints on budgets, economic analysis are important to enhance health resource allocation, especially in countries striving to attain or retain universal access to healthcare for their patients.

In Brazil, the Unified Health System (Sistema Único de Saúde, SUS) provides high cost treatments free of charge for all patients with chronic diseases providing they meet national Clinical Protocols and Therapeutic Guidelines [26,27]. The biologicals (anti-TNF alpha), aminosalycilates and immunomodulators for $\mathrm{CD}$ are available through the Specialized Component of Pharmaceutical Services [28-30]. The indication associated with the dispensation of these medications is recorded in the SUS databases, which also records other health resource utilization such as outpatient procedures and hospitalizations.

Currently, there is a lack of data concerning the epidemiology and expenditure on CD in Brazil. The likely CD incidence and prevalence growth and impact on morbidity and mortality emphasize the need to assess its costs, particularly in a country that is trying to meet its economic challenges and optimize the use of its resources. The aim of this study was to assess the CD-related direct medical costs and changes over time from the perspective of the Brazilian public health system in a fifteen-year follow-up study.

\section{Methods}

A national population-based cohort of Crohn's Disease patient's ages 10-100 years from January 2000 to December 2014 was constructed by deterministic-probabilistic linkage of the following SUS administrative databases: Hospital Information System (SIH), Ambulatory Information System (SIA) and Mortality Information System (SIM) [31].

Patients were identified by the use of the following medications: mesalazine, sulfasalazine, azathioprine, cyclosporine, methotrexate, methylprednisolone, ciprofloxacin, infliximab and adalimumab in combination with $\mathrm{CD}$ diagnosis according to the International Classification of Diseases, 10th Revision (ICD-10) codes K50, K50.0, K50.1, K50.8, K50.9 and M074. Follow-up started at the first date of eligible medication recorded in the period and ended at the date of the last record on one of the databases, death, or December 31, 2014. Only patients with a minimal of 12 months follow-up were retained. Comorbidities developed during the follow-up were identified according to Elixhauser Comorbidity Indicators which is based on the diagnosis provide by ICD codes found in the administrative data [32,33]. Total medical costs were assessed from a public health (SUS) perspective. Costs of outpatient and hospital procedures were based on the values recorded in the SIH and SIA databases. The costs of medications, were determined using the government registered (acquisition) price during the period. All costs were converted to the US dollar adjusted by purchasing power parities (PPP) for each calendar year of the period [34].

Categorical variables were reported by frequency distribution. For continuous variables we calculated the mean and standard deviation (SD) and median (1st and 3rd quartiles) of expenditure per patient by time of follow-up (mean and median annual expenditure) stratified by demographic and clinical variables at study entry, including gender, age category, region of residence, diagnosis according to ICD-10 codes, medication used and respective therapeutic class, and calendar period; and by events that that occurred during the follow-up including medication switch, comorbidity and death. The mean expenditure per patient was also calculated for each year of follow-up by health resource category.

The distribution of the mean annual expenditure per patient was examined to assess normality using histograms and normal probability plots. Univariate and multivariate analyses were subsequently undertaken using a log-linear regression model to evaluate the relation between the demographic and clinical variables and the mean annual expenditure per patient. A threshold of $\mathrm{p}<0.2$ was used to determine which variables would be incorporated into a multivariate regression analysis, with manual backwards elimination. Data analyses were performed using the software $\mathrm{R}$ Studio Version 1.0.143; $\mathrm{p}<0.05$ indicated statistical significance. Subgroup analyses were also conducted dividing study patients in two groups, those who only used medications and those who used medications and other SUS health resources (hospitalizations, outpatient care). This study followed the ethics concepts and was approved by the Research Ethics Committee of the Federal University of Minas Gerais.

\section{Results}

In total, 46,886 patients fulfilled the inclusion criteria (had at least 12 months of follow-up and were 10 to 100 years of age at study entry). Among these, 27,252 (58.1\%) were female, with a ratio of 1.4 women for each man. The majority of patients (63.0\%) were between 26 and 55 years of age at study entry, with a mean age \pm standard deviation of 40.5 \pm 15.5 years. The most common diagnosis at study entry was Crohn's disease of the small intestine (K50.0), with 26,127 (55.7\%) patients in this category. The Brazilian region with the largest number of patients was the Southeast with 29,437 (62.8\%) of the population. The majority of patients $(86.7 \%)$ received monotherapy. Aminosalicylates were the most frequently prescribed medicines at study entry $(62.4 \%)$ and mesalazine was the initial medication in $43.4 \%$ of patients. Medication switch, that indicated the addition of a new medication and/or change for a new one, occurred in 22,223 (47.4\%) of the study population. An appreciable number of patients in the databases, 21,378 (45.6\%) started treatment between 2005 and 2009. Comorbidities developed during the follow-up were identified in $13,762(29.4 \%)$ of the patients and the most frequent were rheumatoid arthritis/collagen vascular diseases affecting $9.3 \%$ of the patients, renal failure (4.5\%), liver disease $(2.9 \%)$ and solid tumor without metastasis (2.3\%). About $5.8 \%$ of the patients died during follow-up. The most common cause of death was noninfectious colitis and enteritis (Table 1).

The mean of follow-up was 5.3 years. The mean annual expenditure per patient over the period was US\$3451.0, 95\% CI [3399.2 3502.7] and varied by the clinical and demographic categories described above. Considering gender and age categories at study entry, higher values were observed among males and ages 18 to 25 years, while among geographic regions and $\mathrm{CD}$ medications, those residing in the centerwest and users of the anti-TNF alpha adalimumab at study entry 
Citation: Machado GD, Godman B, Rahme E, Cherchiglia ML, Acurcio FDA, et al. (2018) Crohn's Disease Treatment Expenditures over Fifteen Years of Follow-Up. Pharmacoeconomics 3: 115. doi:10.4172/2472-1042.1000115

Page 3 of 8

\begin{tabular}{|c|c|c|c|}
\hline Variable & n (\%) & $\begin{array}{l}\text { Mean annual expenditure per } \\
\text { patient US\$ (SD) }\end{array}$ & $\begin{array}{c}\text { Median annual expenditure per } \\
\text { patient US\$ (IQR) }\end{array}$ \\
\hline Total patients & $46886(100.00)$ & 3218.13 (321.58) & $4462(1402-18831)$ \\
\hline \multicolumn{4}{|l|}{ Gender } \\
\hline Female & $27252(58.12)$ & $2867.92(296.44)$ & $4010(1307-16123)$ \\
\hline Male & $19634(41.88)$ & 3704.44 (367.27) & $5323(1554-22892)$ \\
\hline Age mean-years \pm SD & $40.50 \pm 15.51$ & - & - \\
\hline Female & $42.05 \pm 15.33$ & - & - \\
\hline Male & $38.35 \pm 15.49$ & - & - \\
\hline \multicolumn{4}{|l|}{ Age category (years) } \\
\hline $10-17$ & $2418(5.16)$ & $4076.33(415.55)$ & $5785(1373-35262)$ \\
\hline $18-25$ & $6552(13.97)$ & $4262.70(456.79)$ & $6547(1645-28162)$ \\
\hline $26-35$ & $10149(21.65)$ & $3627.52(534.84)$ & $5280(1484-23471)$ \\
\hline $36-45$ & $10484(22.36)$ & $3211.41(202.54)$ & $4461(1433-19101)$ \\
\hline $46-55$ & $8921(19.03)$ & 2691.93 (381.92) & 4027 (1399-15750) \\
\hline $56-65$ & $5319(11.34)$ & $2029.21(603.93)$ & $3639(1280-12311)$ \\
\hline$>65$ & $3043(6.49)$ & $1447.88(552.30)$ & 3639 (1027-7599) \\
\hline \multicolumn{4}{|l|}{ Region of residence } \\
\hline Southeast & $29437(62.78)$ & 3571.82 (336.07) & $5431(1667-22240)$ \\
\hline South & $8281(17.67)$ & $2415.52(410.93)$ & $4289(1457-14135)$ \\
\hline Northeast & $6484(13.83)$ & 2497.02 (498.09) & $1850(736-6728)$ \\
\hline Midwest & $2335(4.98)$ & $3800.57(843.24)$ & 8069 (1878-28036) \\
\hline North & $349(0.74)$ & $3135.14(1505.20)$ & 2447 (865-14159) \\
\hline \multicolumn{4}{|l|}{ Primary diagnosis-ICD-10 } \\
\hline K50-Crohn's disease [regional enteritis] & $7620(16.25)$ & $2759(786.87)$ & $4361,51(1822-15858)$ \\
\hline K50.0-Crohn's disease of small intestine & $26127(55.72)$ & $2979.39(462.48)$ & $4047(1243-17626)$ \\
\hline K50.1-Crohn's disease of large intestine & $5817(12.41)$ & $3650.39(451.20)$ & $5034(1382-21145)$ \\
\hline K50.8-Other Crohn's disease (both small and large intestine) & $5126(10.93)$ & $3842.82(475.69)$ & $5107(1332-22368)$ \\
\hline K50.9-Crohn's disease unspecified & $2142(4.57)$ & $3664.94(632.11)$ & $8448(3088-29271)$ \\
\hline M074-Arthropathy in Crohn disease (regional enteritis) & $54(0.12)$ & $2190.29(986.32)$ & $3944(1498-7307)$ \\
\hline \multicolumn{4}{|l|}{ Pharmaceutical medication class } \\
\hline DMARDs & $29496(62.91)$ & $2553.18(370.98)$ & $3398(1235-10202)$ \\
\hline Immunomodulator & $8601(18.34)$ & $3159.47(582.46)$ & $2461(933-14210)$ \\
\hline Anti-TNF alpha & $3473(7.41)$ & $4325.13(496.73)$ & $7374(23234-68135)$ \\
\hline DMARDs+Immunomodulator & 3407 (7.27) & $9201.15(4639.42)$ & $40840(2508-24292)$ \\
\hline Anti-TNF alpha+Immunomodulator & $741(1.58)$ & $8743.28(4285.05)$ & $32764(20635-50592)$ \\
\hline Anti-TNF alpha+DMARDs & $381(0.81)$ & $8882.70(4922.30)$ & 39747 (21913-64786) \\
\hline Other classes or assotiations & 787 (1.68) & $6172.84(2510.19)$ & $27478(10383-58392)$ \\
\hline \multicolumn{4}{|l|}{ Medication } \\
\hline Mesalazine & $20510(43.74)$ & $2471.55(448.19)$ & $3579(1220-10530)$ \\
\hline Azathioprine & $8447(18.02)$ & $2406.08(608.74)$ & $2333(1247-8901)$ \\
\hline Sulfasalazine & $8285(17.67)$ & $3125.00(589.54)$ & $3001(905-13254)$ \\
\hline Azathioprine+Mesalazine & $2843(6.06)$ & $3524.05(1336.00)$ & $7714(2592-23730)$ \\
\hline Infliximab & $2354(5.02)$ & $9541.15(5051.53)$ & $47218(26075-79121)$ \\
\hline Adalimumab & $1051(2.24)$ & $9873.48(5258.73)$ & 31201 (19618-3267) \\
\hline Other medications or association & $3396(7.24)$ & $5274.17(1803.27)$ & $21464(5671-46921)$ \\
\hline \multicolumn{4}{|l|}{ Period of beginning of treatment } \\
\hline 2000 to 2004 & $8984(19.16)$ & $3023.45(580.69)$ & 6117 (2234-20709) \\
\hline 2005 to 2009 & $21378(45.60)$ & 3023.81 (525.75) & $3945(1447-16385)$ \\
\hline 2010 to 2014 & $16524(35.24)$ & $4014.06(1129.21)$ & $4293(1081-20546)$ \\
\hline \multicolumn{4}{|l|}{ End of follow-up } \\
\hline Loss of follow-up & $44154(94.17)$ & 3202.70 (317.69) & $4391(1375-18927)$ \\
\hline Death & $2732(5.83)$ & 3520.69 (810.03) & $5548(1824-17530)$ \\
\hline \multicolumn{4}{|l|}{ Medication switch } \\
\hline Yes & $22223(47.40)$ & 4512.64 (561.73) & $12612(3717-37307)$ \\
\hline No & $24663(52.60)$ & $1416.09(458.53)$ & $2089(833-6123)$ \\
\hline \multicolumn{4}{|l|}{ Comorbidities } \\
\hline No & $33124(60.6)$ & $2839.27(302.71)$ & $3665(1211-15286)$ \\
\hline
\end{tabular}




\begin{tabular}{|c|c|c|}
\hline \multicolumn{1}{|c|}{ Yes } & $13762(29.4)$ & $3751.16(510.87)$ \\
\hline ICD-10 Groups - Cause of deaths & & \\
\hline Noninfective enteritis and colitis & $377(13.80)$ & $5426.79(1729.74)$ \\
\hline Ischaemic heart diseases & $174(6.37)$ & $3386.55(2172.94)$ \\
\hline Malignant neoplasms of digestive organs & $167(6.11)$ & $3681.27(2296.73)$ \\
\hline Cerebrovascular diseases & $128(4.69)$ & $2728.28(825.28)$ \\
\hline Influenza and pneumonia & $124(4.54)$ & $3154.38(1094.00)$ \\
\hline Other heart diseases & $111(4.06)$ & $2098.92(1042.78)$ \\
\hline Other ICD-10 groups & $1651(60.43)$ & $337(2989-29224)$ \\
\hline
\end{tabular}

Table 1: Demographic and clinical characteristics of CD patients.

showed greater mean annual expenditure. Patients who experienced medication switch, those who developed comorbidities and those who died during follow-up also showed higher mean annual expenditure compared to those without these events, respectively. The highest average cost for patients were found in those who entered the cohort between 2010 and 2014.

The total expenditure between 2000 and 2014 was US\$ 844.68 million, from which US\$ 762.44 million (90.3\%) were for CD medications, US\$ 42.50 million (5.0\%) for other medications, US\$ 25.66 million (3.0\%) for hospitalizations, US\$ 10.12 million (1.2\%) for outpatient care (excluding medications) and US\$ 3.96 million (0.5\%) for diagnostics and monitoring exams.

In the breakdown of expenditures by year of follow-up, medications were the major cost driver in all years, although the ratio of medication to other expenditures fluctuated slightly over the period. An increase in hospitalization expenditures was also apparent throughout the study period (Figure 1)

The evolution of mean annual expenditure per patient in by year of follow-up according to health resource category, showed that mean of $\mathrm{CD}$ medications expenditure was higher in the first year, US\$ 3826.6/ patient, 95\% IC [3732.7 3920.6], and dropped dramatically in the second year for US\$3074.5/ patient, 95\% IC 2998.13150 .9 ], fluctuating slightly in the following years. Among patients that were hospitalized the mean of hospitalization costs were US\$ 1143.0/patient, 95\% IC [1042.5 1243.3], in the first year and fluctuated thereafter, rising considerably in the last two years reaching US\$ 1937.0/patient, 95\% IC [618.9 3254.4]. Other medication expenditures also fluctuated and were higher than those for hospitalizations until the eleventh year. Outpatient care, diagnostics and monitoring exams were less expensive and presented little fluctuations over the study period (Figure 2).

Among the CD medications, the anti-TNF alpha drugs represented $79.1 \%$ of the total medication expenditure overall years, and were also the major cost drivers for all the follow-up years. The evolution of expenditures with anti-TNF alpha during the period showed that the mean annual expenditure per patient was higher in the first year of follow-up and dropped dramatically and consistently until the final years. DMARDs were the second therapeutic class in expenditure followed by immunomodulators. Whilst DMARDs showed a decrease in expenditure by year of follow-up, from 21.8 to $8.7 \%$ of the total expenditures on medications by year, the immunomodulators expenditures rose from $2.1 \%$ to $5.4 \%$ (Figure 3). Ciprofloxacin and methylprednisolone together represented less than $0.5 \%$ of total medication expenditure.

On multivariate analyses, the log-linear model showed that the variables associated with the annual mean total $\mathrm{CD}$-related health expenditures were gender, age category, region of residence, $\mathrm{CD}$ medication used and calendar period at study entry and explained $29.0 \%$ of expenditure (Table 2). Men had an increase of $15.0 \%$ in mean annual expenditure compared to women. All ages category had an increase compared to patients older than 65 years and the higher increase was in ages 18 to 25 years. About the region of residence, reside in North and Northeast at study entry represented a decrease about $36.0 \%$ in mean annual expenditure whilst reside in Southeast and Mid-west represented an increase of $17.0 \%$ and $26.0 \%$, respectively. Among medications used at study entry, compared to sulfasalazine, all medications represented increase in expenditures and it was more significant for the anti-TNF alpha agents, with adalimumab and infliximab representing an increase of 14.80 and 16.15 times the expenditure of patients that used sulfasalazine at study entry. Patients that entered in the study between 2005 and 2009 had 13\% of decrease in expenditures, compared to patients who entered between 2000 and 2004. The subgroup analyses showed that variables associated with mean annual expenditure were the same of the total population model in both groups.

\section{Discussion}

The CD population in Brazil was on average $40.44 \pm 15.56$ years of age at study entry and most of them were female. These findings are concordant with other epidemiological data reported by Lowe, et al [35] that showed slight female predominance among Canadian CD patients and an average age at diagnosis of 38.7 years. Another study conducted by Benedini et al. in Italy included CD patients with mean age at diagnosis of 43 years [24] and although men were a minority in that study, they showed a mean annual expenditure higher than that of women as found in our study.

The majority of $\mathrm{CD}$ patients in our study were diagnosed as having $\mathrm{CD}$ of the small intestine (ICD-10 K50.1). Although the unadjusted annual mean expenditures seemed higher for those diagnosed as other CD (K50.8) that affected both the small and large intestine, adjusted analyses showed a non-significant result. Studies have reported that Ileocolonic disease localization is associated with a complicated course of disease and may explain higher expenditure among patients with both small and large intestine disease [36]. However, this finding could not be examined in our data because the ICD-10 classification for CD is limited in terms of information on disease location that is provided only in a general way. Although disease behavior (structuring or penetrating) and extension of anatomical involvement are relevant to predict CD outcomes [37], they could not be assessed in our study.

The comparison between patients who had a medication switch, comorbidity and death and those without the event showed that mean annual expenditure was higher in patients that subsequently died and in those with comorbidities who may represent a group of patients with 


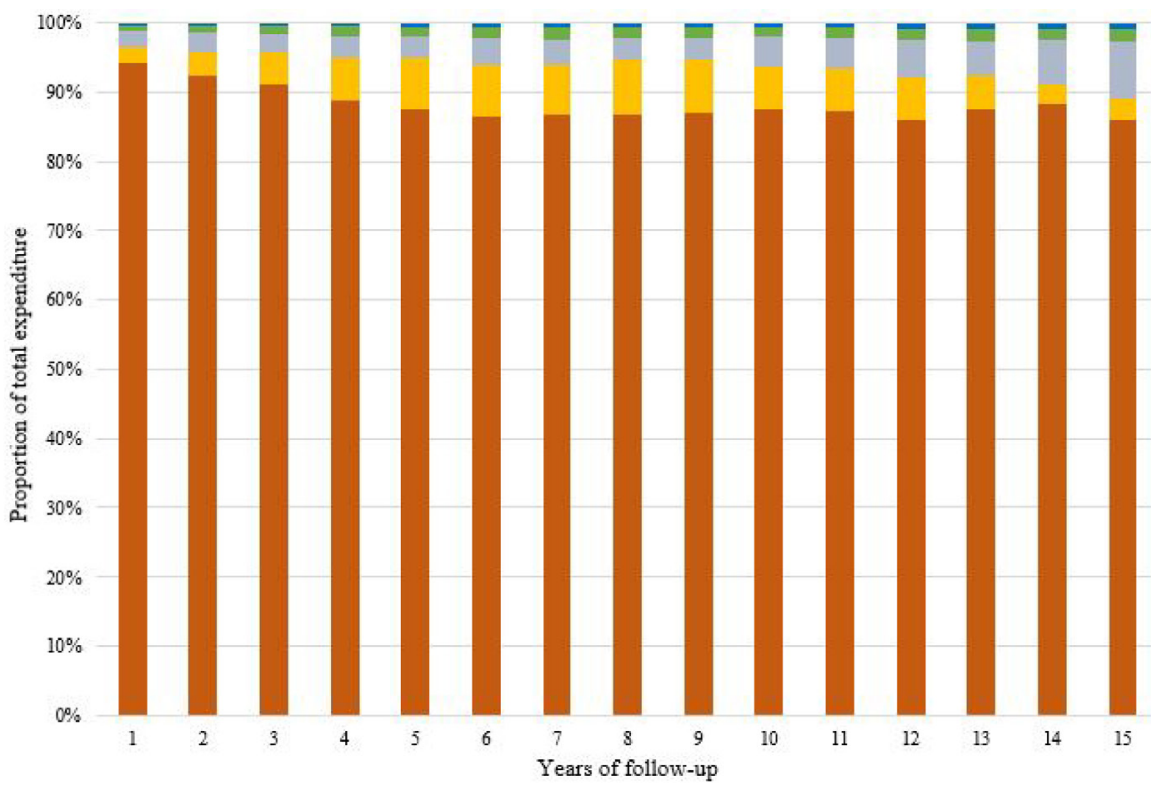

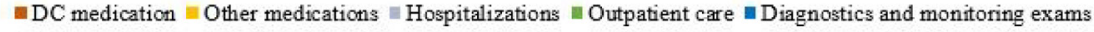

Figure 1: Distribution of total expenditure by health category resource and year of follow-up.

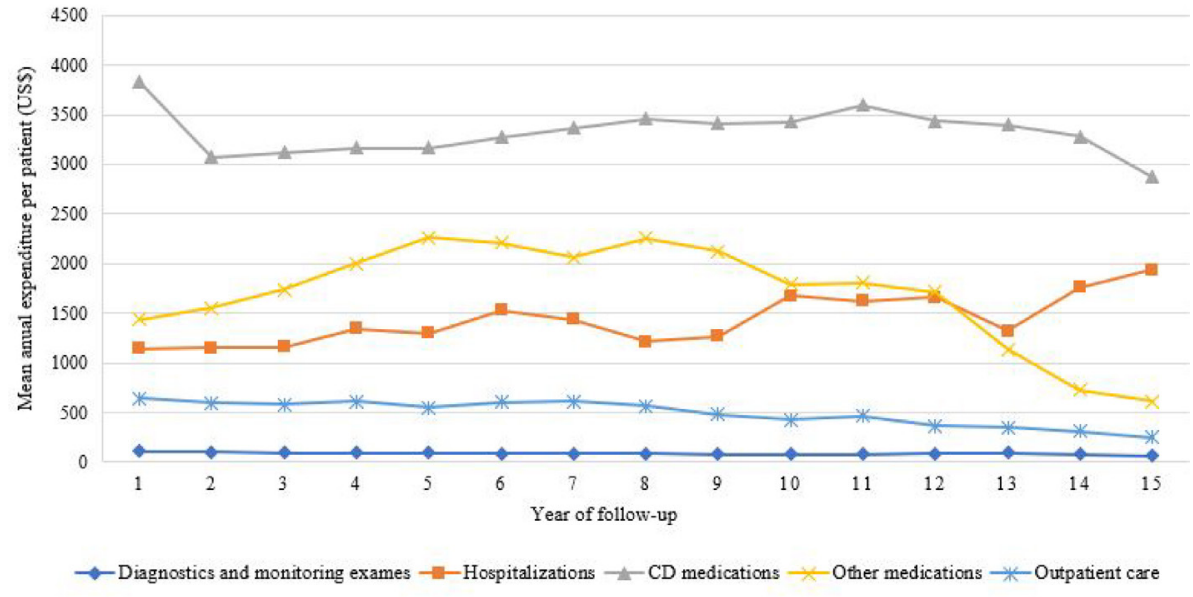

Figure 2: Mean annual expenditure per patient by health resource and year of follow-up.

more severe disease and more complications resulting in more health resource utilization. Higher expenditures also occurred in the group of patients with medication switch and can be explained by the fact that in general CD patients start the treatment with not so expensive medications like aminosalicylates following to the high cost medications anti-TNF alpha agents. Besides that, medication switch is indicative of therapeutic failure and/or increase of disease severity, which demand more intensive care. Although the occurrence of these events suggests a higher expenditure, a specific and more robust analysis would be required to evaluate their relation with the expenditure.

Mesalazine was the most prescribed medication at treatment onset, confirming its traditional use as a first line therapy in patients with mild to moderate $\mathrm{CD}$ disease [38]. Although a lower proportion of patients started with anti-TNF alpha medication, these represented the highest annual mean expenditure as was expected since the antiTNF alpha are the most costly medications in the management of CD. The introduction of adalimumab in 2010 may explain a higher annual average expenditure for patients who started treatment between 2010 and 2014.

The higher mean expenditure per patient for CD medication in the first year can be associated to high doses medication utilization in patients that are using medications to induce remission and the need of switch medication in case of failure of the first line treatment. Bernstein and colleagues found that costs of CD treatment were greater in the first year of diagnosis and decreased in the following years [39] as showed for CD medications in our study. The exception in our study was for hospitalization outlay, which increased during this period. A prospective study of CD patients with fifteen years follow-up [40] 


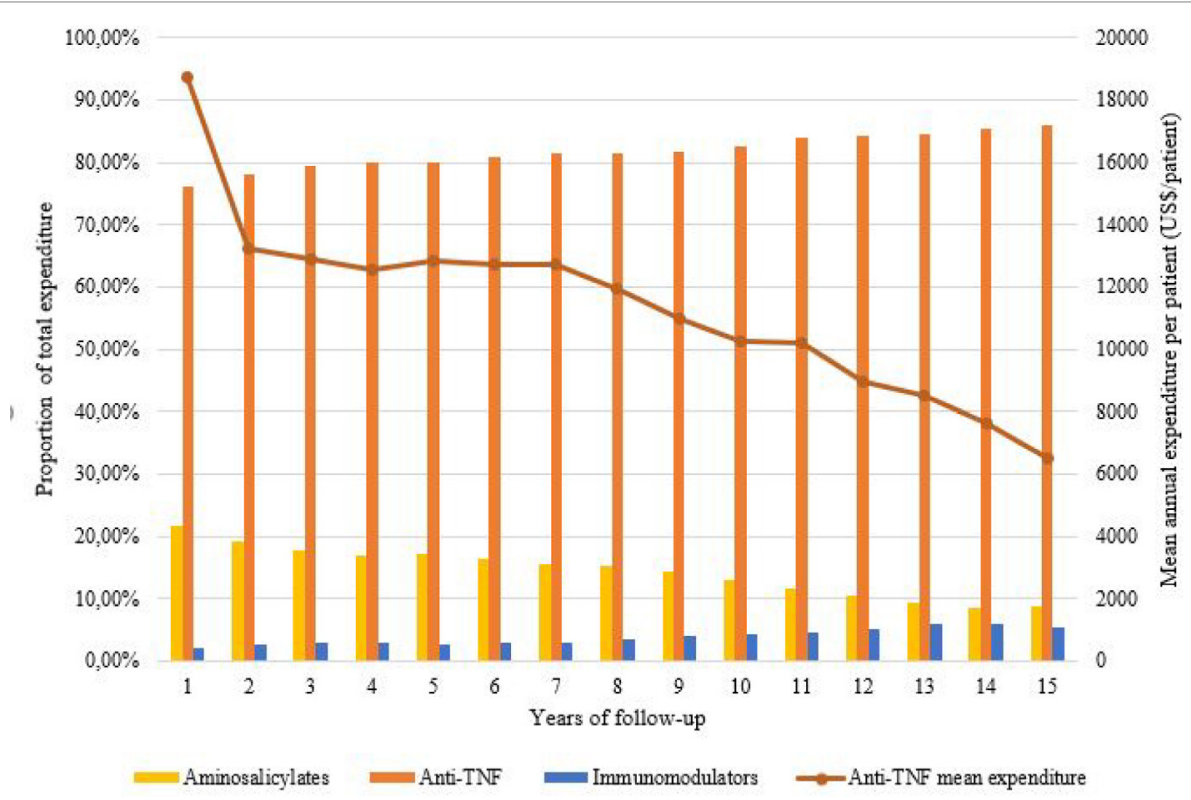

Figure 3: Distribution of CD medications expenditures by therapeutic class according to each year of follow-up and mean annual expenditure per patient of anti-TNF alpha medications.

\begin{tabular}{|c|c|c|c|c|c|}
\hline Variable & Beta coefficient & Exp (Coefficient) & Standard error & t value & $\operatorname{Pr}(>|t|)$ \\
\hline Intercept & 6.190390 & 488.04 & 0.030923 & 200.184 & $<0.001$ \\
\hline Male & 0.139731 & 1.15 & 0.012409 & 11.261 & $<0.001$ \\
\hline 2005 to $2009 / 2000$ to 2004 & -0.138133 & 0.87 & 0.012479 & -11.069 & $<0.001$ \\
\hline 10 to 17 years/>65 years & 0.369707 & 1.45 & 0.036052 & 10.255 & $<0.001$ \\
\hline 18 to 25 years $/>65$ years & 0.484038 & 1.62 & 0.029014 & 16.683 & $<0.001$ \\
\hline 26 to 35 years $/>65$ years & 0.383023 & 1.47 & 0.027278 & 14.041 & $<0.001$ \\
\hline 36 to 45 years $/>65$ years & 0.264105 & 1.30 & 0.027132 & 9.734 & $<0.001$ \\
\hline 46 to 55 years $/>65$ years & 0.232816 & 1.26 & 0.027613 & 8.431 & $<0.001$ \\
\hline 56 to 65 years $/>65$ years & 0.133650 & 1.14 & 0.029862 & 4.476 & $<0.001$ \\
\hline North/South & -0.449768 & 0.64 & 0.071863 & -6.259 & $<0.001$ \\
\hline Northeast/South & -0.451238 & 0.64 & 0.021865 & -20.637 & $<0.001$ \\
\hline Southeast/South & 0.159956 & 1.17 & 0.016396 & 9.756 & $<0.001$ \\
\hline Midwest/South & 0.230715 & 1.26 & 0.030897 & 7.467 & $<0.001$ \\
\hline Mesalazine/Sulfasalazine & 0.267712 & 1.31 & 0.017088 & 15.667 & $<0.001$ \\
\hline Azathioprine/Sulfasalazine & 0.008098 & 1.01 & 0.020401 & 0.397 & 0.691 \\
\hline Azathioprine+Mesalazine/Sulfasalazine & 1.016734 & 2.76 & 0.028642 & 35.498 & $<0.001$ \\
\hline Infliximab/Sulfasalazine & 2.785832 & 16.21 & 0.030768 & 90.542 & $<0.001$ \\
\hline Adalimumab/Sulfasalazine & 2.698644 & 14.86 & 0.043517 & 62.014 & $<0.001$ \\
\hline Other medications or associations/Sulfasalazine & 1.618767 & 5.05 & 0.026809 & 60.382 & $<0.001$ \\
\hline
\end{tabular}

Table 2: Multivariate analysis result.

showed that hospitalizations were required for only few patients, and this was most common in the early years, in contrast with our findings. However, the same study compared the mild and moderate to severe $\mathrm{CD}$ and it was observed that for patients with severe disease, disease activity and hospitalizations in subsequent years were more frequent than in those with mild and moderate CD. These findings may help to explain the increase of hospitalizations in the last years of our study follow-up, since part of the patients with more time of follow-up might have severe disease and needed of hospitalization.

The breakdown of expenditures showed that $\mathrm{CD}$ medications accounted for the highest proportion of health expenditure for these patients, followed by other medications and hospitalizations. Analyzing the proportion by year of follow-up, medications also represented the majority of expenditures over time, and in the final follow-up years hospitalization was the second cost driver. Anti-TNF alpha agents represented $71.4 \%$ of the total health resource expenditures and $79.1 \%$ of total expenditures on $\mathrm{CD}$ medications being the most cost driver in all years of follow-up. Among medications, the proportion on the expenditures on anti-TNF alpha increased over time from $76.0 \%$ to $85.9 \%$.

A large European cohort, with ten years of follow-up that ended in 2004 showed different proportions on expenditures, with medical and 
surgery hospitalizations being the most expensive resource representing $63 \%$ of total expenditures with medications being responsible for $30 \%$ [41]. Similarly, in a six-month retrospective follow-up of 172 patients in UK, from June to December 2000, medical and surgical hospitalization contributed to $60 \%$ of total costs and less than $20 \%$ was attributed to medications [2]. Differences between these earlier studies and ours may be explained by the limited availability of the anti-TNF alpha medications during the earlier study periods.

A study by Kappelman et al., conducted in the US based on data from 87 health plans covering 33 states, between 2003 and 2004, found that $31 \%$ of the costs were attributable to hospitalization, $33 \%$ to outpatient care, and $35 \%$ to pharmaceutical claims, with mean annual costs of US $\$ 8265$ [42]. Another population-based study conducted in Manitoba, Canada using health services administrative databases between 2005 and 2006, showed that $5 \%$ of the costs were on outpatient care, $39 \%$ on hospital inpatient, $12 \%$ on physician office visits and $44 \%$ on medications [39]. Data from a prospective longitudinal study of 24 months, between 2010 and 2011, in the Netherlands, showed that the proportion of anti-TNF alpha therapy-related costs increased from $64.0 \%$ to $72.0 \%$ whilst hospitalization costs decreased from $19.0 \%$ to $13.0 \%$ [43]. As in our study, these reports reveal that biologic treatments account for the majority of the CD cost, while hospitalization that used to be the most expensive CD treatment, are now responsible for a small proportion of that cost.

In the breakdown of expenditures among $\mathrm{CD}$ medications by year of follow-up, the decrease in the proportion of aminosalicylates followed by an increase in the proportion of immunomodulators can be explained by the fact that aminosalicylates are more indicated in mild to moderate disease and are more effective to induce remission than for maintenance therapy while immunomodulators, apart from anti-TNF alpha, are effective in remission and maintenance therapy, being more used in the subsequent years of treatment. The increase of the proportion of anti-TNF alpha agents followed the disease course, and their increasing use is probably due to more active or severe disease that didn't response to aminosalicylates or initial immunomodulators, reflecting their growing role in the treatment of patients with CD. The decrease in mean annual expenditure per patient of anti-TNF alpha during the period is a result of using higher doses in the first weeks of treatment to induce remission, what contribute for a greater expenditure in first year of treatment, but is followed by a decrease during the maintenance therapy.

In our study, multivariate analyses showed an increase in mean annual expenditure for men what can be attributed to higher health resource utilization in this group than among the women in our study. The higher increase in expenditure in younger patients About the age category, some studies have reported that increasing age of diagnosis was associated with less complicated disease $[44,45]$, what can be associated with less costs in treatment and can explain the greater increase on expenditure for patients that were younger at study entry. The increase in expenditures for Southeast and Midwest regions residents can be justified by the fact they are more developed regions [46] and have a greater access to health services [47] as well as a higher relation of gastroenterologists per capita [48] compared to North and Northeast, which result in more health resource utilization and more prescription medications, increasing the costs of treatment. The higher increase in expenditure for those patients, who used antiTNF alpha agents adalimumab or infliximab at study entry, showed the great impact of their use on CD treatment costs, attributed mainly to their high unitary value, and highlighted the contribution of these medications in $\mathrm{CD}$ costs.
We believe the strength of this study is the population size and the inclusion of nationwide $\mathrm{CD}$ patients. Limitations included the utilization of information from administrative database that contains records of utilization and payment of procedures and does not provide clinical data about the disease. This did not allow evaluation of expenditures according to disease severity or activity. Other limitations include the fact that in Brazil $25.0 \%$ of the population have private health care insurance [49] and hospitalizations that are paid for privately could not be included in our study. This though has no to little impact on medication expenditures since high-cost drugs are more available and accessible in SUS. Besides that, moderate to severe $\mathrm{CD}$ patients are heavy health resource users and are more likely to use public resources. Therefore, our study is more likely to have missed some mild CD patients.

Overall, we believe our findings are robust and provide guidance to national and regional health authorities in Brazil regarding current expenditures on patients with $\mathrm{CD}$, and their component parts. Medication costs may start to decrease with greater availability and use of biosimilars worldwide, with up to $60 \%$ discounts reported in some countries [50].

\section{Conclusion}

CD medications represented the greatest proportion of expenditure in managing $\mathrm{CD}$ patients, with anti-TNF alpha agents being the greatest cost driver and total outlay. Trends with the increasing use of biologics in the management of CD patients worldwide show the need and relevance of cost-effectiveness analyses. These data of real life drug utilization can be useful to enhance future cost-effectiveness studies in $\mathrm{CD}$, as well as provide benchmark figures for health authority personnel in Brazil and wider.

\section{References}

1. Loftus EV Jr (2004) Clinical epidemiology of inflammatory bowel disease: Incidence, prevalence and environmental influences. Gastroenterology 126 1504-1517.

2. Bassi A, Dodd S, Williamson P, Bodger K (2004) Cost of illness of inflammatory bowel disease in the UK: a single centre retrospective study. Gut 53: 1471 1478 .

3. Kostic M, Djakovic L, Sujic R, Godman B, Jankovic SM (2017) Inflammatory bowel diseases (Crohn's Disease and Ulcerative Colitis): Cost of treatment in Serbia and the implications. Appl Health Econ Health Policy 15: 85-93.

4. Feuerstein JD, Cheifetz AS (2017) Crohn disease: Epidemiology, diagnosis and management. Mayo Clin Proc 92: 1088-1103.

5. Lichtenstein GR, Hanauer SB, Sandborn WJ (2009) Practice Parameters Committee of American College of Gastroenterology. Management of Crohn's disease in adults. Am J Gastroenterol 104: 465-483.

6. Travis SP, Stange EF, Lémann M, Oresland T, Chowers Y, et al. (2006) European evidence based consensus on the diagnosis and management of Crohn's disease: Current management. Gut 55: i16-35.

7. Juillerat P, Vader JP, Felley C, Pittet V, Gonvers JJ, et al. (2009) Appropriate maintenance treatment for Crohn's disease: Results of a multidisciplinary international expert panel-EPACT II. J Crohns Colitis 3: 241-249.

8. Buchanan J, Wordsworth S, Ahmad T, Perrin A, Vermeire S, et al. (2011) Managing the long term care of inflammatory bowel disease patients: The cost to European health care providers. J Crohns Colitis 5: 301-316.

9. Duveau N, Nachury M, Boualit M, Gerard R, Branche J, et al. (2017) Adalimumab dose escalation is effective and well tolerated in Crohn's disease patients with secondary loss of response to adalimumab. Dig Liver Dis 49: 163-169.

10. Strik AS, Bots SJ, D'Haens G, Lowenberg M (2016) Optimization of antiTNF therapy in patients with Inflammatory Bowel Disease. Expert Rev Clin Pharmacol 9: 429-439. 
11. Huoponen S, Blom M (2015) A systematic review of the cost-effectiveness of biologics for the treatment of Inflammatory Bowel Diseases. PloS One 10 e0145087.

12. Floyd DN, Langham S, Severac HC, Levesque BG (2015) The economic and quality-of-life burden of Crohn's disease in Europe and the United States, 2000 to 2013: A systematic review. Dig Dis Sci 60: 299-312.

13. Putrik P, Ramiro S, Kvien TK, Sokka T, Pavlova M, et al. (2014) Inequities in access to biologic and synthetic DMARDs across 46 European countries. Ann Rheum Dis 73: 198-206.

14. Molodecky NA, Soon IS, Rabi DM, Ghali WA, Ferris M, et al. (2012) Increasing incidence and prevalence of the inflammatory bowel diseases with time, based on systematic review. Gastroenterology 142: 46-54.

15. Burisch J, Jess T, Martinato M, Lakatos PL, ECCO-EpiCom (2013) The burden of inflammatory bowel disease in Europe. J Crohns Colitis 7: 322-337.

16. Kappelman MD, Rifas-Shiman SL, Kleinman K, Ollendorf D, Bousvaros A, et al. (2007) The prevalence and geographic distribution of Crohn's disease and ulcerative colitis in the United States. Clin Gastroenterol Hepatol 5: 1424-1429.

17. Victoria CR, Sassak LY, Nunes HR (2009) Incidence and prevalence rates of inflammatory bowel diseases, in Midwestern of São Paulo State, Brazil. Arq Gastroenterol 46: 20-25.

18. Souza MHLP, Troncon LEA, Rodrigues CM, Viana CFV, Onofre PHC, et al (2002) Evolução da ocorrência (1980-1999) da doença de Crohn e da retocolite ulcerativa ildiopática e análise das suas características clínicas em um hospital universitário do sudeste do Brasil. Arq Gastroenterol 39: 98-105.

19. Parente JML, Coy CSR, Campelo V, Parente MPPD, Costa LA, et al. (2015) Inflammatory bowel disease in an underdeveloped region of Northeastern Brazil. World J Gastroenterol 21: 1197-1206.

20. Ganz ML, Sugarman R, Wang R, Hansen BB, Hakan-Bloch J (2016) The economic and health-related impact of Crohn's disease in the United States: Evidence from a nationally representative survey. Inflamm Bowel Dis 22: 1032-1041.

21. Rocchi A, Benchimol El, Bernstein CN, Bitton A, Feagan B, et al. (2012) Inflammatory bowel disease: A Canadian burden of illness review. Can J Gastroenterol 26: 811-817.

22. Gibson TB, Ng E, Ozminkowski RJ, Wang S, Burton WN, et al. (2008) The direct and indirect cost burden of Crohn's disease and ulcerative colitis. J Occup Environ Med 50: 1261-1272.

23. Stark R, Konig HH, Leidl R (2006) Costs of inflammatory bowel disease in Germany. Pharmacoeconomics 24: 797-814.

24. Benedini V, Caporaso N, Corazza GR, Rossi Z, Fornaciari G, et al. (2012) Burden of Crohn's disease: Economics and quality of life aspects in Italy. Clinicoecon Outcomes Res 4: 209-218.

25. Juan J, Estiarte R, Colome E, Artes M, Jimenez FJ, et al. (2003) Burden of illness of Crohn's disease in Spain. Dig Liver Dis 35: 853-861.

26. de Souza AL, de Assis Acurcio F, Júnior AA, do Nascimento RC, Godman $B$, et al. (2014) Insulin glargine in a Brazilian state: Should the government disinvest? An assessment based on a systematic review. Appl Health Econ Health Policy 12: 19-32.

27. Costa JO, Godman B, Fischer MA, Dartnell J, Heaney A, et al. (2016) Implementation of clinical guidelines in Brazil: Should academic detailing be used? Jn Pharm Health Services Res 7: 105-115.

28. Ministério da Saúde, Brasil (2002) Portaria $n^{\circ} 858$, de 12 de novembro de 2002. Aprova o Protocolo Clínico e Diretrizes Terapêuticas da Doença de Crohn.

29. Ministério da Saúde, Brasil (2010). Portaria $n^{\circ} 711$, de 17 de dezembro de 2010. Aprova o Protocolo Clínico e Diretrizes Terapêuticas da Doença de Crohn. Brasília: Diário Oficial da União, 17 de dezembro de 2010.

30. Ministério da Saúde, Brasil (2014). Portaria $n^{\circ}$ 966, de 2 de outubro de 2014. Aprova o Protocolo Clínico e Diretrizes Terapêuticas da Doença de Crohn. Brasília: Diário Oficial da União, 2 de outubro de 2014
31. Queiroz OV, Guerra Jr AA, Machado CJ, Andrade EIG, Meira Jr W, et al. (2010) Relacionamento de registros de grandes bases de dados: estimativa de parâmetros e validação dos resultados, aplicados ao relacionamento dos registros das autorizações de procedimentos ambulatoriais de alta complexidade com os registros de sistema de informações hospitalares. Cad. Saúde Colet 18: 298-308.

32. Elixhauser A, Steiner C, Harris DR, Coffey RM (1998) Comorbidity measures for use with administrative data. Med Care 36: 8-27.

33. Quan H, Sundararajan V, Halfon P, Fong A, Burnand B, et al. (2005) Coding algorithms for defining comorbidities in ICD-9-CM and ICD-10 administrative data. Medical Care 1: 1130-1139.

34. The World Bank. PPP conversion factor

35. Lowe AM, Roy PO, B-Poulin M, Michel P, Bitton A, et al. (2009) Epidemiology of Crohn's Disease in Québec, Canada. Inflamm Bowel Dis 15: 429-435.

36. Oostenbrug LE, Collard A, Oger AF, Degroote E, Aboul Nasr EI Yafi FA et al. (2006) Clinical outcome of Crohn's disease according to the Vienna classification: Disease location is a useful predictor of disease course. Eur $J$ Gastroenterol Hepatol 18: 255-261.

37. Torres J, Caprioli F, Katsanos KH, Lobatón T, Micic D, et al. (2016) Predicting outcomes to optimize disease management in inflammatory bowel diseases. $J$ Crohns Colitis 10: 1385-1394.

38. Campregher C, Gasche C (2011) Aminosalicylates. Best Pract Res Clin Gastroenterol 25: 535-546.

39. Bernstein CN, Longobardi T, Finlayson G, Blanchard JF (2011) Direct medica cost of managing ibd patients: A Canadian Population-based study. Inflamm Bowel Dis 18: 1498-508

40. Cosnes J, Bourrier A, Nion-Larmurier I, Sokol H, Beaugerie L, et al. (2012) Factors affecting outcomes in Crohn's disease over 15 years.Gut 61: 1140-1145.

41. Odes S, Vardi H, Friger M, Wolters F, Russel MG, et al. (2012) Cost analysis and cost determinants in a European inflammatory bowel disease inception cohort with 10 years of follow-up evaluation. Gastroenterology 131: 719-728.

42. Kappelman MD, Rifas-Shiman SL, Porter CQ, Ollendorf DA, Sandler RS, et al. (2008) Direct health care costs of Crohn's disease and ulcerative colitis in us children and adults. Gastroenterology 135: 1907-1913.

43. van der Valk ME, Mangen MJ, Severs M, van der Have M, Dijkstra G, et al (2016) Evolution of costs of inflammatory bowel disease over two years of follow-up. PLoS One 11: e0142481.

44. Tremaine WJ, Timmons LJ, Loftus Jr EV, Pardi DS, Sandborn WJ, et al. (2007) Age at onset of inflammatory bowel disease and the risk of surgery for nonneoplastic bowel disease. Aliment Pharmacol Ther 25: 1435-1441.

45. Polito JM , Childs B, Mellits ED, Tokayer AZ, Harris ML, et al. (1996) Crohn's disease: Influence of age at diagnosis on site and clinical type of disease. Gastroenterology 111: 580-586

46. Brasília DF (2017) PROGRAMA DAS NAÇÕES UNIDAS PARA O DESENVOLVIMENTO-PNUD.

47. Stopa SR, Malta DC, Monteiro CN, Szwarcwald CL, Goldbaum M, et al. (2017) Use of and access to health services in Brazil, 2013 National Health Survey. Rev Saude Publica $51: 3 \mathrm{~s}$

48. Conselho Federal de Medicina,Conselho Regional de Medicina de São Paulo (2015) Demografia médica no Brasil 2015. p: 284.

49. Soares IS, Ugá DMA, Porto SM. (2008) O mix público-privado no Sistema de Saúde Brasileiro: financiamento, oferta e utilização de serviços de saúde. Ciência \& Saúde Coletiva 13(5): 1431-1440.

50. Matusewicz W, Godman B, Pedersen HB, Furst J, Gulbinovic J, et al. (2015) Improving the managed introduction of new medicines: Sharing experiences to aid authorities across Europe. Expert Rev Pharmacoecon Outcomes Res 15: $755-758$. 